\title{
COST-BENEFIT ANALYSIS (CBA) OF SUSTAINABLE DRAINAGE SYSTEMS (SUDS) RETROFIT: A CASE STUDY
}

\author{
OLUWAYEMI A. OLADUNJOYE, DAVID G. PROVERBS, BECK COLLINS \& HONG XIAO \\ School of Engineering and the Built Environment, Birmingham City University, UK
}

\begin{abstract}
The retrofit of Sustainable Drainage Systems (SuDS) has been applied successfully to properties to help mitigate future flooding and to deliver other benefits to properties, such as improvements in air and water quality, economic benefits and improved business reputation. However, the uptake of SuDS retrofit has been low due to a lack of understanding of the true costs and benefits and concerns about long-term maintenance. This study presents a cost-benefit analysis (CBA) of the monetary and non-monetary values of SuDS retrofit in the context of an individual property, in this case, a leisure centre. A qualitative study was carried out comprising a series of interviews with stakeholders to the property, an analysis of documentary evidence and observations on the site. The findings demonstrate the importance of teamwork amongst the stakeholders during the decision-making process in helping to overcome many of the known challenges. The willingness to pay process is used to value the tangible and intangible benefits arising from the scheme. The installation would provide a net value to the client of well over $£ 100,000$ over a 10 -year period versus the installation costs of $£ 39,000$ and the return on investment would be achieved in just 3 years. The findings highlight many of the apparent barriers that need to be overcome when installing retrofit schemes and clearly demonstrate the importance of the intangible benefits derived. It is recommended that these are given full consideration at the decision-making stage and in supporting the uptake of the retrofit of SuDS.
\end{abstract}

Keywords: SuDS retrofit, flood, leisure centre, costs, benefits and maintenance.

\section{INTRODUCTION}

Flooding is an increasing hazard, which regularly impacts towns and cities in the UK [1]. The impacts range from self-evident damage to the built environment to intangible effects such as long-term disruption to the economic health of affected regions where infrastructure has been compromised. The summer 2007 floods highlighted the significant hazards associated with surface water flooding [2] when intense precipitation overwhelmed drainage systems and created surface flows, which flooded over 35,000 properties in England and Wales [3]. This caused much disruption to lives and properties which was estimated to be worth about $£ 3$ billion.

In 2019, there were several deaths caused by flooding events, many thousands of people had their lives and livelihoods devastated, critical infrastructure was damaged and many essential services were disrupted [4]. Many of the affected regions still have to cope with the traumatic consequences of the flooding events that occurred in their location. With the rise in urban housing, climate change effects and more flooding events, further losses are envisaged if deliberate actions are not taken to manage the rising hazards.

A further impact of the urbanising world is the spread of impermeable surfaces which increases apace as greater numbers live in urban environments [5]. Increases in hard-standing through urbanisation will increase flood risk by reducing available permeable ground and a range of other ecosystem services. It is possible to return parts of the built environment to a more natural state when done sensitively by the use of SuDS, which could also offer a range of ecosystem benefits such as fresh soil and atmosphere, a balanced and regulated climate, 
healthy food for humans and wildlife: other benefits include improvements in aesthetics, biodiversity and air quality [6], which may be of interest to policymakers.

Retrofitting SuDS to attenuate storm-water runoff has been advocated as part of an integrated solution required to address this problem [7]; however, its uptake has been low [6]. A few barriers have been identified as part of the reasons for the low uptake, such as the lack of experience and trust in such schemes, and that SuDS tend to be undervalued by stakeholders owing to the complexity of the monetisation and quantification of their wider benefits. Further research is therefore needed to help develop a fuller appreciation of the true costs and the wider monetary and non-monetary benefits towards addressing some of the apparent barriers to the retrofit of SuDS [8].

An earlier phase of this research reported the development of a conceptual cost-benefit analysis (CBA) model of the retrofit of SuDS [6]. This study reports the empirical findings of the application of this CBA model to an individual property, in this case, a leisure centre.

\subsection{SuDS Retrofit}

SuDS is a generic term that refers to various measures aimed at managing surface water runoff and consequent flooding and pollution problems from urban catchments [9]. SuDS is defined as the management of rainwater, which includes snow and other precipitation, with the aim of reducing damage caused by flooding events, improving the quality of water, the improvement and protection of the environment, the improvement and safety of the health of the residents and the process of ensuring the effective stability and durability of drainage systems [10].

SuDS come in a variety of forms, but unlike conventional and outdated drainage systems currently used in urban areas, SuDS focus on slowing down and reducing the amount of surface water runoff, as well as encouraging natural infiltration of water [11]. It is therefore essential that SuDS are carefully designed and take into account characteristics such as the scale of the development and exposure to surface water flooding; there is no 'one size fits all' solution. Often the best SuDS scheme and components are those that have involved a range of expertise in their design.

New developments offer an important opportunity to improve the management of surface water, however, this requires early consideration of drainage and SuDS in the development planning process. Nevertheless, new developments form only a small part of the current urban area, and it is equally important to consider how the resilience of existing urban developments might be improved. Eighty per cent of the existing building stock in the UK will be in place in 2050 and so we need to consider ways to adapt these built environments to the changing climate [12]. This raises concerns about what the future of existing buildings will be if measures are not being carried out to manage the risks of damage to these properties.

SuDS retrofit is a storm-water management process, which is aimed at addressing urban water quality and the problems associated with flooding [13]. There is limited experience of retrofitting SuDS in the UK, and there are no well-established procedures for evaluating the feasibility, value or cost-effectiveness of doing this. However, there remains growing interest in the introduction of this technology [9] and stakeholders and researchers have sought to develop modalities on how to make SuDS more acceptable and relevant within the UK [14]. Examples of retrofitting SuDS can be seen in the installation of green roofs, the diversion of roof drainage from a combined sewer system into rain gardens, the conveyance of road runoff via roadside swales into a pond sited in an area of open space [10]. These represent alternative ways of influencing the quality of the water downstream and the problems relating to it, thereby providing a more effective, resilient and sustainable approach. 


\subsection{Method of Study}

A case study methodology was adopted for the study, and as recommended by Yin [11], data were gathered and triangulated from three sources, namely documentary evidence, observations and focus group discussions with key stakeholders. The primary source of evidence was drawn from a focus group with three of the key stakeholders that were involved in the implementation of the scheme, including a representative of the client (Participant A), the property manager (Participant B) and the Parish council secretary to the trustees (Participant C). A round table session held within the leisure centre with these three stakeholders included outline questions including the decision-making process, their perception of flood risk, the costs of installation and maintenance and importantly their views on the benefits. This helped to achieve a robust and balanced view of the parties involved.

The documentary evidence was obtained from quotations showing details about the costs, the scheme, architectural drawings, the specification of the SuDS scheme and the 'before and after' pictures of the leisure centre. Furthermore, an observatory procedure in the form of a site survey was used to obtain evidence of the scheme in confirming the details given by the stakeholders.

\subsection{The SuDS Retrofit Scheme}

The case study is a leisure centre that was built as a community project to offer a range of facilities including a sports hall, fitness suite, fitness classes, grass pitches and AstroTurf pitches. A SuDS retrofit scheme was installed on the site in 2016 with the intention of helping to manage flood events, whilst also providing educational, aesthetic, social and health benefits for the property and the community. Figure 1 shows the frontage to the leisure centre, which was previously a wide expanse of concrete block paving, punctuated only by two small circular tree pits.

Figure 2 shows the construction stage and the current state of the swale at the leisure centre. This wetland swale has been lined, in order to prevent the risk of subsidence within the sloped banks of the adjacent ditch and to create a wetland habitat that compliments the habitat of the ditch.

The swale receives input via four downpipes to the rear of the building: draining $365 \mathrm{~m}^{2}$ of roof catchment on the western side of the building. The swale can hold $10 \mathrm{~m}^{3}$, a little over that which is necessary for the 1 in 10-year storm event for the catchment area.

Figure 3 shows the current intervention for runoff. Previously, all rainwater collected from roofs and hard surfacing at the leisure centre would discharge directly into the stream behind the leisure centre but now the stream eventually flows into the River Mease.
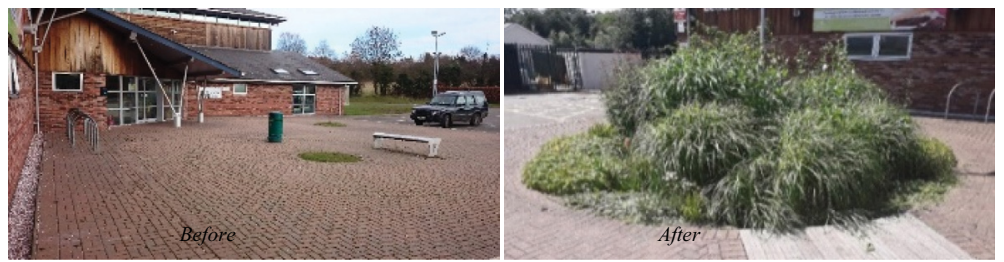

Figure 1: Before and after pictures of the outlook of the frontage of the site featuring one of the rain gardens. 

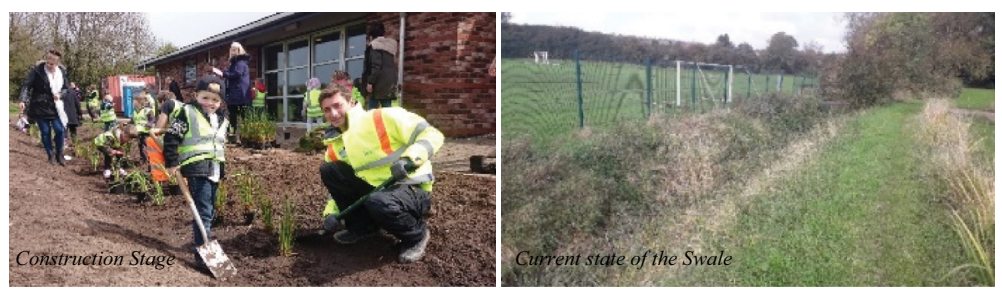

Figure 2: During the construction of the Swale and after.

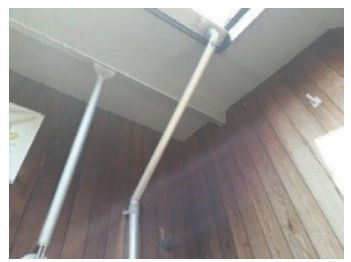

Figure 3: Runoff from the front roofs of the leisure centre designed to complement the existing metal rainwater goods of the building

\subsection{SuDS Design}

The SuDS design is a combination of four different components; rain gardens, lined swale basin, basket controlled outlets and stainless steel architectural rain channels. This project used landscape to reduce flood risk and pollution by delivering a controlled flow of clean water into the River. To develop the SuDS rationale, natural flow paths were analysed and landscape zones were broadly divided.

The entrance to the leisure centre is enhanced by the inclusion of two large rain gardens; replacing previously underperforming tree pits and adding year-round aesthetics. Each side is joined (hydraulically) by a bridge, which means that should water level rise, it will happen simultaneously in each feature. The rain gardens receive rainwater from an area of $675 \mathrm{~m}^{2}$, including adjacent hard standing and half of the parapet roof. They are capable of storing $16.8 \mathrm{~m}^{3}$ water: accommodating up to the 1 in a 10 -year storm event. The planting choice is such that a simple management routine (annual cut of perennials and grasses in February) can be implemented.

In channelling the runoff from the roof, two stainless steel rills were introduced, which skirt each flank of the building and are designed to complement the existing metal rainwater goods of the building. The rills are raised only slightly from the ground and are able to collect water from four downpipes. Each rill outlets rainwater at its centre to the head of a blockwork channel. These surface channels are shallow enough to traverse the pedestrian entrance area, prior to entering the two large rain gardens. In order to store and treat the rainwater from the south-facing element of this parapet roof, two downpipes are diverted towards the rain gardens at the entrance. This rearrangement of downpipes extends the catchment area by $190 \mathrm{~m}^{2}$.

Another component is the swale, which receives input via four downpipes to the rear of the building: positively draining $365 \mathrm{~m}^{2}$ of roof catchment on the western side of the building. A control orifice, housed in a gabion basket, drains the swale at no more than 5 litres/ second/ha. 
It was determined that amenity benefits could be sought through the addition of rain gardens to the front, while biodiversity improvements could be made to the rear, to link with adjacent existing habitats, by holding water in a lined Wetland Swale.

\section{RESULTS AND FINDINGS}

This section discusses the factors that influenced the decision-making process including the perception of flood risk, the costs of installing the scheme, the process of obtaining the funds and the maintenance procedure of the scheme. Particular emphasis is placed on explaining the perceived benefits and the value of these from the perspective of the key stakeholders.

\subsection{Decision-making process}

The focus group session involved three participants. These stakeholders were fully involved from the beginning of the project and with the daily running of the leisure centre. The involvement of different stakeholders and other factors that influenced the decision-making process were discussed.

\subsubsection{Stakeholder involvement}

At the inception of the SuDS retrofit scheme, the main stakeholders involved were the property manager, a council representative (the property owner), a consultant, the contractor, the landscape architect and the client. This was confirmed by one of the participants in the focus group section:

...Yes, we were all involved. We had meetings where we met quite frequently to discuss the project. (Participant B)

This was considered very important because it confirmed the level of support which was necessary to drive the delivery of the project and helped to establish a strong team ethos among the stakeholders. This provided the opportunity to sell the idea for a SuDS retrofit installation to the council and for them to understand the need for the scheme. This also provided a means to secure the necessary funding for the scheme. For example, one of the participants said;

...well, I could not force it on them. Not that would have been the way even if I could. So unless we got a lot of support, it won't be worth doing. (Participant A)

Statements such as the above show that the decision to install a SuDS scheme needs to be owned by the stakeholders to the property. Key to this is helping to convey a clear understanding of the benefits of SuDS.

Furthermore, an expert was on the team to provide the required guidance and knowledge of the scheme and to bring clarity and understanding to the process. '...Fray, he knew what criteria was needed and what to do. They are leaders in doing this all work. I mean theory I could have designed it myself, but you know, I didn't have as much experience and the liability factor was important. So we got them to do it in case anything goes wrong'. (Participant A)

\subsection{Flood Perception}

While this property had no record of previous flooding, the close proximity of the River Mease, including the threat of surface water runoff, clearly influenced the decision to install SuDS. '... because of the rainfall from the roof because it was a concern...there is a 
watercourse behind that it could slump in' (Participant A). The presence of the river and the potential risk in the neighbourhood could pose a future risk for the property, and this makes the siting of the scheme a very important one.

\subsection{Funding and costs of installation}

Funding for the scheme was handled by the Manager from Water group, who prepared the application and submitted this to the Environment Agency Regional Flood Committee. This was confirmed by one of the participants:

'...But she did the paperwork, put it into the regional flood committee and they funded it' (Participant A). The documentation included the architectural drawings, the estimated cost of the scheme and a written proposal which was compiled by the client.

Furthermore, it was identified that obtaining the required funds could have some effect on the overall delivery, and so they chose to delay any further action until the required funds were acquired. This is reflected in the statement made by one of the participants; '...we didn't progress the scheme until we actually had funding to do it'. (Participant A)

Table 1 shows a breakdown of the costs of installing the scheme obtained from documentary evidence and the focus group discussions.

The additional cost during the construction process was accrued as a result of one of the subcontractors who caused some delay to the project. This led to the need to employ additional workers on the project to speed up the process and this attracted some extra funds.

...The only problem I said we encountered was with the subcontractor at that time it took them ages. And that was quite frustrating...I mean they were okay but we did have a slight change of staff and I don't think we put enough staff on. (Participant A)

\subsection{Maintenance and operation}

Maintenance of the scheme was only considered to some extent at the design stage where it was hoped that the costs could be absorbed within the routine maintenance of the property. This was highlighted by one of the participants:

Well, we didn't put a cost to it because we said we'd absorb it with our maintenance guys with some extra hours. But we've been really lucky that the medical units have set up a gardening club as part of their social prescribing scheme, and they come and look after it (Participant C) .... and this guaranteed the ongoing maintenance as well as which we said that can be an issue with the Parish Council. (Participant B)

Participants also identified the role of the community in terms of their contribution to maintaining the scheme. Two different groups volunteered to maintain the scheme. The first is the local gardening club '.. and we have the local gardening club come to look after the plants'

Table 1: Costs of SuDS retrofit installation

\begin{tabular}{lllll}
\hline Cost item & SuDS design & $\begin{array}{l}\text { SuDS cost at } \\
\text { tender }\end{array}$ & Final SuDS cost & $\begin{array}{l}\text { Overall cost including } \\
\text { roof water channelling }\end{array}$ \\
\hline Amount $(£)$ & 5,000 & 35,000 & 39,000 & 65,000 \\
\hline
\end{tabular}


while the local school also helps to maintain the SuDS scheme. 'When they did the planting, the school came down to it'.

\subsection{Benefits from SuDS retrofit Installation}

The uptake of SuDS retrofit could be of benefit to different stakeholders including the property owners and users and the wider community. This has been reflected in the scheme and confirmed by the participants at the focus group section.

...I think the benefits of doing it within a site like this as a community facility, so the community see it, so when they come in, they see the scheme and they appreciate the scheme. (Participant B)

The scheme has had a positive impact on visitors to the leisure centre including tourists and members of the local community. It has also led to other SuDS schemes being installed within the community.

...I mean, you have loads of people coming to look at the scheme. Yeah, you use it as a model scheme...And since then we've raised more funds and we've done a SuDS scheme down there (town centre). (Participant A)

Another significant benefit to the community is the health benefit, which has influenced different groups and individuals and has encouraged volunteers to come forward and assist with the maintenance. '.. and we have the local gardening club come to look after the plants that you know, part of their social prescribing, through the doctors, GP referrals and things like that. So as part of their health and social benefits, that's what they do' (Participant C). Hence, there is little concern about the ongoing maintenance of the scheme and the costs have remained very low.

Focus group participants were asked to quantify the benefits and how much they would be willing to pay for these. Figure 4 provides a summary of these findings.

The participants found it difficult to put a value against many of these benefits, especially the intangible benefits as expressed by one of the participants. '...It is absolutely difficult to quantify because how do you put a price on wellbeing' (Participant B). It was evident that some of the benefits had not been considered during the design and had not influenced the decision-making process. Nevertheless, the participants were able to provide approximate values based on their perceptions of these benefits in the context of the leisure centre scheme.

A CBA was undertaken by calculating the net value (NV) and the net present value (NPV) of the SuDS retrofit project, assuming investment returns within 10 years, as per [10], [18]. Using the average of the upper and lower benefit intervals (see Fig. 4), the total value of the benefit in the present year and turn the total benefit in 10 years was derived. The cost of installation was then subtracted from the total value of the benefit accrued over 10 years. Importantly, no maintenance costs were included in the analysis, reflecting the use of volunteers on the scheme.

Below is a calculation for the NV of the entire project in 10 years:

Net cost $=$ present cost of installation + maintenance cost

$$
=£ 39,000+0=£ 39,000
$$




\section{WTP value of Benefits of the Leisure centre}

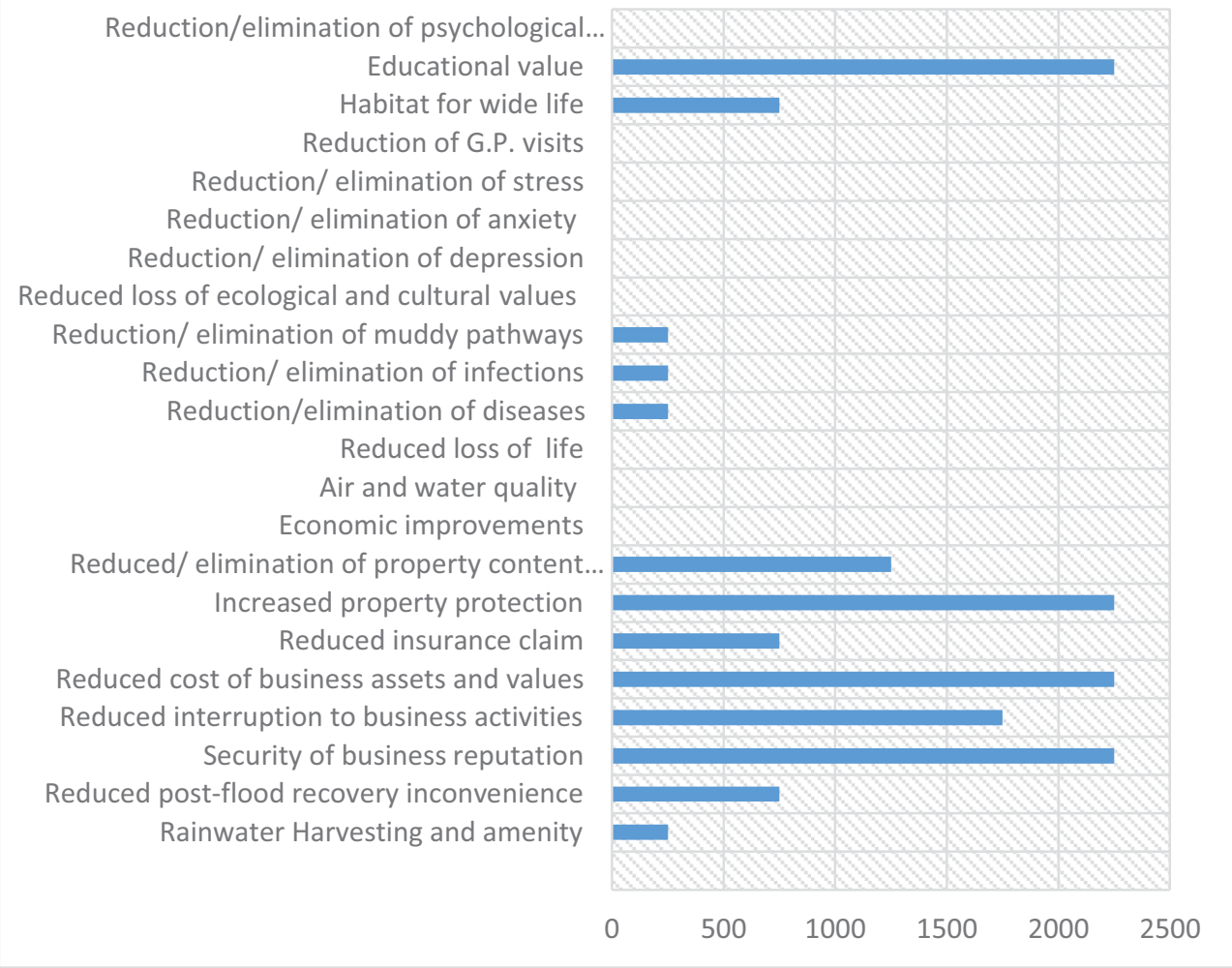

Figure 4: Willingness-to-pay value of benefits of the leisure centre

Net benefit in 10 years $=$ total benefit/annum $\times 10$

$$
=£ 152,565
$$

Hence,

Net value in 10 years $=$ Net Benefit in 10 years - Net Cost

$$
\begin{aligned}
& =152,565-39,000 \\
& =£ 113,565
\end{aligned}
$$

\section{DISCUSSIONS}

In view of the findings presented above, several key inferences can be made in relation to the cost and the benefits of installing SuDS retrofit and the decision-making process. It can be seen that various factors influenced the implementation of the scheme including the perception of flood risk, the costs of installation, funding, maintenance and some if not all of the benefits.

Stakeholder involvement on this project was encouraging, and a good team ethos was evident. This was helpful in making sure that the costs of installation were well understood and well defined. Research has shown that there is often a lack of interest by stakeholders in new 
schemes [12], [8]. However, in this case, the response from the stakeholders was different and could be adjudged as positive; perhaps indicating that the view of SuDS is beginning to change and its necessity is beginning to be accepted. Proactive response from a member of the team to lead on fundraising for the project demonstrated that the stakeholders were very much committed to implementing the project. This helped to prevent any unforeseen delays in implementation and helped to drive the scheme at every stage. One of the stakeholders had a lot of experience with SuDS, and this made it easier to work through the design and construction stages. This positively influenced the other stakeholders to take up the scheme [8] and helped to overcome previously reported barriers concerning a lack of knowledge [12].

The perception of flood risk among the stakeholders was clearly a major factor that influenced the installation of SuDS. Research has shown that the impact of flood events can be very destructive to properties and the reputation of businesses and activities [14], [12], [21]. Within the leisure centre, it was important that the effect of flooding was controlled both on the building and the outdoor sports centre. The data obtained for this property suggest that runoff from the roof to the property and also the flow of surface water at the football pitch were detrimental to the centre and needed to be controlled. In discussing the outcome, reference was made to the fact that all surface water from all parts of the property including the roof has been channelled to the swale and then to the river Mease for easy runoff.

Funding for this sort of retrofit is not part of standard maintenance budgets and so this represented a key challenge. Many organisations are unlikely to consider SuDS retrofit as a priority when considering their financial returns and therefore securing sufficient funds represents a barrier [15], [16], [19]. In the case of the leisure centre, money was sought from different avenues like flood committees and specialised organisations. This could have delayed the implementation of the scheme but this was made easier due to the fact that someone was well informed about channels of funding. To ease the difficulty of obtaining funds, it could be useful to have specialised guidance and support for this purpose. This could include advice on managing the cost of installation and on-going maintenance.

During the focus group discussions, a number of benefits were identified; however, many of these had not been considered during the decision-making process. There was no attempt to quantify the benefits of the scheme. Earlier research has identified this as one of the major barriers to the uptake of SuDS retrofit [8], [14]. The willingness-to-pay process revealed the difficulties posed in quantifying these benefits, especially the intangible benefits. Research has shown that intangible benefits by their subjective nature are difficult to quantify and are said to be more personal to the victims of flood events [8], [6], [17], [20]. It was, therefore, important to carry out this exercise in order to obtain a full understanding of the benefits of the SuDS scheme to the property owners and to propose an appropriate procedure of eliciting the intangible benefits of the scheme.

\section{CONCLUSIONS}

The study has investigated the costs and the benefits of the installation of SuDS retrofit at a leisure centre including some of the key decision-making issues. The importance of teamwork amongst the stakeholders during the decision-making process clearly helped to overcome many of the known challenges. It was clear that maintenance had not been fully considered, and fortunately, this was being undertaken by volunteers at no cost to the council. The willingness-to-pay process has shown that the perceived benefits from the scheme were valued at around $£ 15,000$. A number of intangible benefits were valued highly (i.e. educational, reputation) thus demonstrating the need to capture these in the decision making process. It 
was found that the installation would provide a NV to the client of well over $£ 100,000$ over a 10 -year period and that the return on investment would be achieved in just 3 years.

This study has undertaken the first CBA of the retrofit of SuDS, using a conceptual model developed earlier in the research. The findings highlighted many of the apparent barriers that need to be overcome when installing retrofit schemes. The results clearly demonstrate the importance of the intangible benefits derived, and it is recommended that these are given full consideration at the decision-making stage and in promoting the uptake of the retrofit of SuDS.

\section{REFERENCES}

[1] Webber, J. L., Fu, G., \& Butler, D., Comparing cost-effectiveness of surface water flood management interventions in a UK catchment. Journal of Flood Risk Management, e12523, 2019.

[2] Pitt, M., Learning lessons from the 2007 floods (p. 505). London: Cabinet Office, 2008.

[3] Abubakar, A. M., Elrehail, H., Alatailat, M. A., \& Elçi, A., Knowledge management, decision-making style and organizational performance. Journal of Innovation \& Knowledge, 4(2), 104-114, 2019.

[4] Brinkmann, R., Interconnections in Environmental Sustainability: Water and Energy. In Environmental Sustainability in a Time of Change (pp. 195-216). Palgrave Macmillan, Cham, 2020.

[5] Jha, B., Cueto-Felgueroso, L., \& Juanes, R., Fluid mixing from viscous fingering. Physical review letters, 106(19), 194502, 2011.

[6] Oladunjoye, O. A., Proverbs, D. G., Collins, B., \& Xiao, H., A cost-benefit analysis model for the retrofit of sustainable urban drainage systems towards improved flood risk mitigation. International Journal of Building Pathology and Adaptation, 2019.

[7] Lamond, J. E., Rose, C. B., \& Booth, C. A., Evidence for improved urban flood resilience by sustainable drainage retrofit. Proceedings of the Institution of Civil EngineersUrban Design and Planning, 168(2), 101-111, 2014.

[8] Oladunjoye, O. A., Proverbs, D. G., Collins, B., "The barriers and opportunities to the retrofit of sustainable urban drainage systems (SuDS) towards improving flood risk mitigation in urban areas in the UK", International Sustainable Ecological Engineering Design for Society (SEEDS) Conference: Conference Proceedings, Leeds Sustainability Institute, pp. 420-431, 2017.

[9] Stovin, V., Poë, S. and Berretta, C., "A modelling study of long term green roof retention performance", Journal of Environmental Management, Vol. 131, pp. 206-215, 2013. DOI: 10.1016/j. jenvman.2013.09.026.

[10] Chambers, D., Spaenjers, C., \& Steiner, E. (2019). The Rate of Return on Real Estate: Long-Run Micro-Level Evidence. Available at SSRN 3407236.

[11] Lloyd, P., Sustainable Urban Drainage Systems (SUDS): a proactive approach to reducing surface flooding, 2019.

[12] Castleton, H. F., Stovin, V., Beck, S. B., \& Davison, J. B., Green roofs; building energy savings and the potential for retrofit. Energy and Buildings, 42(10), 1582-1591, 2010.

[13] Walsh, C. J., et al, Principles for urban stormwater management to protect stream ecosystems. Freshwater Science, 35(1), 398-411, 2016. https://doi.org/10.1086/685284

[14] Carboni, D., Gluhak, A., McCann, J.A. and Beach, T.H., "Contextualising water use in residential settings: a survey of non-intrusive techniques and approaches", Sensors, Vol. 16 No. 5, p. 738, 2016.

[15] Roelich, K., Financing infrastructure and built environment adaptation to climate change. University of Leeds, 2015. 
[16] Sustainable Development Commission, The future is local: empowering communities to improve their neighbourhoods, 2010.

[17] Joseph, R., Proverbs, D., Lamond, J., \& Wassell, P., Application of the concept of costbenefit analysis (CBA) to property level flood risk adaptation measures. Structural Survey, 2014.

[18] Domínguez, I., Ward, S., Mendoza, J. G., Rincón, C. I., \& Oviedo-Ocaña, E. R., Enduser cost-benefit prioritization for selecting rainwater harvesting and greywater reuse in social housing. Water, 9(7), 516, 2017.

[19] Cimato, F., \& Mullan, M., Adapting to climate change: analysing the role of government. Defra Evidence and Analysis Series, Paper, 1, 2010.

[20] Yang, F., Tan, J., \& Peng, L., The effect of risk perception on the willingness to purchase hazard insurance-A case study in the Three Gorges Reservoir region, China. International Journal of Disaster Risk Reduction, 101379, 2019.

[21] Kuhlicke, C., et al, Multiple flood experiences and social resilience: findings from three surveys on households and companies exposed to the 2013 flood in Germany. Weather, climate, and society, 12(1), 63-88, 2020. 